\title{
A tonada Palhaço: comicidade ritual presente na Danza de Tijeras da Sequia Tusuy, em Puquio - Peru ${ }^{1}$
}

\author{
La tonada Payaso: comicidad ritual presente en la Danza de Tijeras de la \\ Sequia Tusuy, en Puquio - Perú \\ The 'tonada Palhaço': the ritualistic humor in Tijeras Dance during \\ Sequia Tusuy in Puquio - Peru
}

\author{
Ana Carolina Fialho de Abreu ${ }^{2}$
}

\begin{abstract}
Resumo
Neste artigo, resultado de uma pesquisa exploratória que faz parte do meu período de doutorado co-tutela no Peru, no curso de Antropologia da Universidad Nacional Mayor de San Marcos busco sensivelmente revelar um espírito, dialogar com outra cultura, descrever com esmero algumas sequências da tonada Palhaço, presente no extenso repertório das (os) Danzantes de Tijeras, que no povoado de Puquio, nos Andes de Ayacucho competem representando a um ayllu (bairro) ou a uma família quechua. A Sequia Tusuy (Festa da Água) acontece no mês de agosto e setembro. Este momento do ano marca a subida dos Auquis (velhos sábios sacerdotes indígenas) até o ponto mais alto da cordilheira, nas huacas ou lugares sagrados para trazer a "água nova". Nesta festa os Danzantes de Tijeras realizam o chamado atipanakuy, repertório completo de sua dança. A tonada Palhaço é um momento cômico desta jornada ritual em dança. Trata-se de "jogos" divertidos onde o público se torna protagonista. Conclui-se que mesmo sendo a Danza de Tijeras considerada em 2010 pela UNESCO como Patrimônio Cultural Imaterial da Humanidade, seus músicos e suas (seus) danzantes, em sua grande maioria vivem em duras condições na capital e em outras cidades do Peru.
\end{abstract}

Palavras-Chave: Comicidade; Danza de Tijeras; Tonada Palhaço; Sequia Tusuy.

\section{Resumen}

En este artículo, resultado de una investigación exploratoria que hace parte de mi estancia de doctorado co-tutela en Perú, en el curso de Antropología de la Universidad Nacional Mayor de San Marcos busco sencillamente revelar un espíritu, dialogar con otra cultura, describir con esmero algunas secuencias de la tonada Payaso, presente en el extenso repertorio de las (os) Danzantes de Tijeras que en el pueblo de Puquio, en los Andes de Ayacucho compiten representando a un ayllu (barrio) o a una familia quechua. La Sequia Tusuy (Fiesta del Agua) se sucede en el mes de agosto y septiembre. Este momento del año marca la subida de los Auquis (viejos sabios sacerdotes indígenas) hasta el punto más alto de la cordillera, en las huacas o lugares sagrados para traer el "agua nueva". En esta fiesta los Danzantes de Tijeras realizan el llamado atipanakuy, repertorio completo de su danza. La tonada Payaso es un momento cómico de esta jornada ritual de danza. Se trata pues de "juegos" divertidos donde el público se torna protagonista. Se concluye que mismo siendo considerada en 2010 por la

\footnotetext{
${ }^{1}$ Artigo apresentado no Simpósio Temático Experiências Estéticas com a Arte enquanto Cultura durante o II Seminário Latino-Americano de Estudos em Cultura - SEMLACult em Foz do Iguaçu/PR, Brasil, 2018.

${ }^{2}$ Doutoranda no Programa de Pós Graduação em Artes Cênicas pela Universidade Federal da Bahia (UFBA), com co-Tutela em Antropologia na Universidad Nacional Mayor de San Marcos (UNMSM); Professora no curso de Licenciatura em Teatro na Universidade Federal do Tocantins (UFT); Palmas, Tocantins, Brasil; anacarolinaabreu1886@gmail.com.
} 
UNESCO como Patrimonio Cultural de la Humanidad, sus músicos y suyas (os) danzantes, en su gran mayoría viven en duras condiciones en la capital y en otras ciudades de Perú.

Palabras claves: Comicidad; Danza de Tijeras; Tonada Payaso; Sequia Tusuy.

\begin{abstract}
In the essay, result of an exploratory research during my $\mathrm{PhD}$ in Peru in the Universidad Nacional Mayor Antropology course of San Marcos, I try to display a mood, to communicate with another culture, to describe accurately some sequences of Tonada Palhaço, part of the Tijeras Dancers wide repertory that in the Puquio neighborhood, in the Ayacucho Andes, competes representing a ayllu, (a neighborhood) or a quechua family. The Sequia Tusuy (The Water Festival) happens in August and September. That period identifies the rise of Auquis (old and wise indigenous priests) to the top of the mountains, in the huacas, or holy places, to take "new water". In that festival, the Tijeras Dancers, perform the so-called atipanakuy, an outright repertory of their dance. The Tonada Palhaço is an amusing moment of this ritualistic journey expressed through dance; it's about jokes in which the public becomes the protagonist. It's possible to infer that, even if the Tijeiras Dance was considered as Intangible Cultural Heritage by UNESCO in 2010, most of its musicians and dancers live under harsh condition in the capital and other cities of Peru.
\end{abstract}

Keywords: Humor; Tijeras Dance; Tonada Palhaço; Sequia Tusuy.

\title{
1. Introdução: Seguia Tusuy (Festa da Água)
}

Neste artigo a arte atua como mediadora dos afetos e se faz senhora das boas relações. O meu lugar de fala (o lugar de onde se vê e se fala) pressupõe o diálogo enquanto reconhecimento do outro, pensar lugar de fala é uma postura ética. Sou mulher, brasileira, palhaça e professora de teatro e estive presente na Sequia Tusuy (Festa da Água) de Puquio no Peru em 2016 e 2017, para a pesquisa de campo do meu doutorado em Artes Cênicas com cotutela em Antropologia. Não sou uma Danzante de Tijeras, não sou peruana, não nasci em Puquio e mesmo prolongando minha permanência nesta comunidade nunca chegarei a conhecer todos os elementos do universo ideológico da Sequia Tusuy, sua espiritualidade, seus "protagonistas" 3 e a comicidade nela presente.

Em um trabalho de campo, exploratório como este, entendido como uma prática de investigação dentro da formação profissional de antropólogas (os) da Universidad Nacional Mayor de San Marcos, localizada em Lima, capital do Peru, onde estudo atualmente, se busca sensivelmente revelar um espírito, alcança apenas parte do proposto, ou seja, o fundamental para a conformação desse universo e deixa para estudos posteriores seu aprofundamento, que deve acontecer principalmente pela voz das pessoas da comunidade e pelas (os) próprias (os) Danzantes de Tijeras a quem eu agradeço o acolhimento, a troca e o diálogo ao longo dos últimos três anos.

\footnotetext{
${ }^{3}$ Os vocábulos do mundo do teatro são usados, neste trabalho, de modo metafórico.
} 
Puquio é capital da província de Lucanas, localizada na zona sul do departamento de Ayacucho, na cordilheira andina, há 3.200 metros sobre o nível do mar. Trata-se da província onde a presença da população indígena falante da língua quechua é mais forte, alcançando em torno de $70 \%$ nos anos cinquenta. Segundo o senhor Juan Francisco Tincopa Calle (2016, p.4), nascido em Puquio, desde os tempos imemoriais, a cada ano, comemora-se esta festa. Nos meses de agosto, nos ayllus (bairros) de Pichqachuri, Qayau e Chaupi e no mês de setembro, no ayllu (bairro) de Qollana.

Sobre a imagem que tenho da chegada em Puquio, na minha incapacidade de descrevê-la, compartilho as palavras do escritor e antropólogo José Maria Arguedas, uma das figuras mais expressivas no processo de aproximação e de incorporação da cultura indígena de origem andina, quechua, à literatura latino-americana encontrada na primeira página de sua novela Yawar Fiesta, escrita em 1941:

Entre alfafares, chacras de trigo, de habas y cebadad sobre una lomada desigual está el pueblo. Desde el abra de Sillanayok' se ven tres riachuelos que corren, acercándose poco a poco a medida que van llegando a la quebrada del rio grande. Los riachuelos bajan de las punas corriendo por un cause brusco, pero se tienden después en una pampa desigual donde hay hasta una lagunita; termina la pampa y el cause de los ríos se quebra otra vez y el agua va saltando de catarata en catarata hasta llegar al fondo de la quebrada. El pueblo se ve grande, sobre el cerro, siguiendo la lomada; los techos de teja suben desde la orilla de un riachuelo, donde crecen algunos eucaliptos, hasta la cumbre; en la cumbre se acaban, porque el filo de la lomada esta el jirón Bolívar, donde viven los vecinos principales, y allí los techos son blancos de calamina. En las faldas del cerro, casi sin calles, entre chacras de cebada, con grandes corrales y patios donde se levantan yaretas y molles frondosos, está la casa de los comuneros, los ayllus de Puquio, se ven como pueblo indio. Pueblo indio, sobre la lomada, junto a un riachuelo. Desde el abra de Sillanayok' se ven tres ayllus: Pichk achuri, K'ayau, Chaupi. -iPueblo indio! dicen los viajeros cuando llegan a esa cumbre y divisan Puquio. Unos hablan con desprecio; tritan de frío en la cumbre los costeños, y hablan: - ¡Pueblo indio! (...) (ARGUEDAS, 1983, p.122).

A Sequia Tusuy é uma celebração ancestral coletiva de profundo sentido espiritual que celebra a água que é vida, sangue que desce das montanhas, essência que vincula e harmoniza a convivência dos seres vivos, humanos e não humanos. Os principais atores sociais da festa são os auquis (sacerdotes indígenas) e seus pongos (assistentes) - encarregados de cumprir com toda a parte espiritual do ritual -, que farão possível a chegada da gratidão dos ayllus até os wamanis $^{4}$ (espíritos dos deuses que habitam os nevados e as montanhas) e a pachamama (Mãe Terra) (ver fotografia 1).

\footnotetext{
${ }^{4}$ Existem wamanis maiores e menores. Pedrorqo é considerado o maior de Puquio e Qarwarasu o maior de toda a região. Cada ayllu tem seus auquis e pongos e ambos fazem as oferendas a distintos wamanis (espíritos) que habitam distintos apus (montanhas).
} 
Segundo o antropólogo peruano Rodrigo Montoya Rojas (2015, p.5), professor emérito da Universidad Nacional Mayor de San Marcos, nascido em Puquio e co-orientador da minha pesquisa, há dois mil anos, os habitantes dos vales andinos subiam até os apus da sua região com oferendas para agradecer aos wamanis e a pachamama pela água recebida no ano agrícola que termina e para rogar pela água do ano seguinte. Atualmente, com sua agricultura de irrigação, a Sequia Tusuy é considerada a celebração indígena originária mais importante do seu calendário anual.

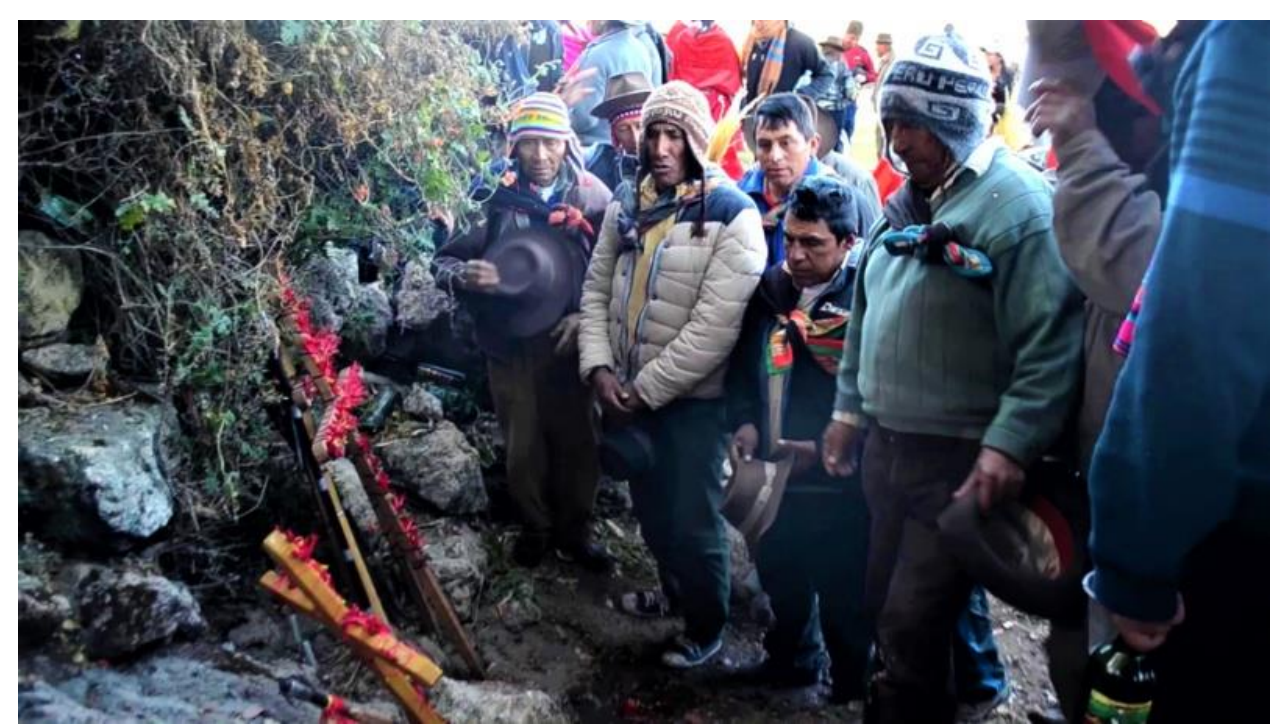

Fotografia 1 - Da esquerda para a direita: auquis do ayllu de Pichqachuri: Hilarión Garriazo de la Cruz, Miguel Rivera Canales e seus pongos (assistentes). Fonte: Ana Carolina Abreu. Agosto de 2017.

Meu interesse principal era conhecer os llamichu, cômicos rituais que segundo Montoya (2015, p.5) representam a consciência ancestral que se move pelo ar, dando giros com seu humor próprio em quechua, perseguindo a cada um e a cada uma durante vários momentos da festa, com a implícita intenção de inquietar a mente dos irmãos "aculturados" e estimular sua memória ancestral. Os llamichu gritam e saúdam a água, ocupam todo o povoado com ruidosos badalos adornados, brincando, fazendo imprecações e todo mundo rir. No meio da festa, os llamichu colocam para correr os homens que representam os nacaq (conquistadores espanhóis). Trata-se, segundo Montoya (2015, p.6), de uma confrontação simbólica entre espanhóis ou "mestiços" e os quechuas originários (ver fotografia 2). 


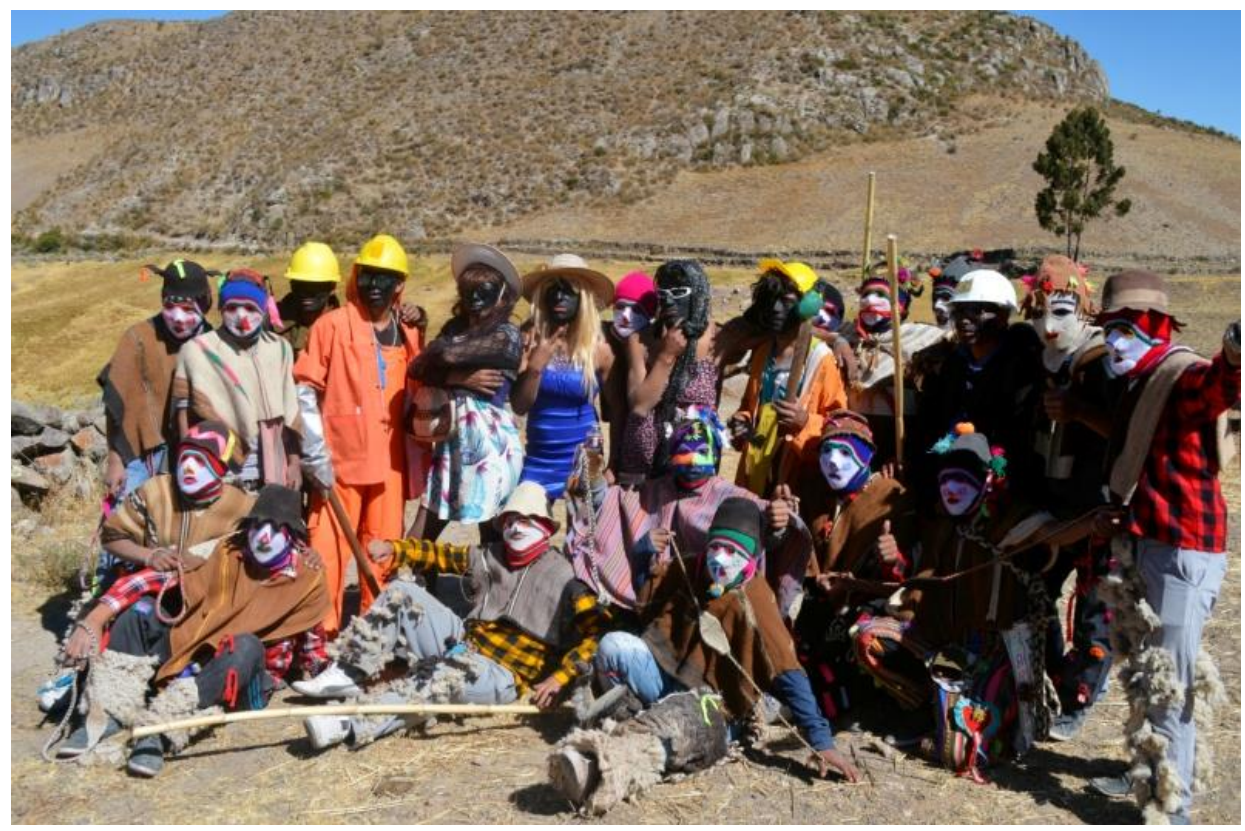

Fotografia 2 -Llamichu e Nacaq do bairro de Qollana. Fonte: Ana Carolina Abreu. Setembro de 2016.

Os (as) Danzantes de Tijeras, conhecidos como Danzaq (ver fotografia 3), também são “protagonistas” desta celebração. São pessoas físicas que emprestam seu corpo para que o espírito do wamani se manifeste, mostrando sua beleza, sua harmonia, seu poder e sua capacidade fraternal de estar guiando as vidas das pessoas deste povo como ayllus (famílias), ou seja, como coletividades conectadas a pachamama (CALLE, 2016, p.4). Ressalto que, desde o dia que cheguei ao Peru tive a oportunidade de participar de diversos congressos, encontros e apresentações em vários espaços produzidos pelos músicos e pelos (as) Danzantes de Tijeras, o que fez com que eu conhecesse pouco a pouco a dimensão da dança, suas peculiaridades e distintas características quando apresentada na serra (nos rituais e festas andinas) e na capital (cidade). 


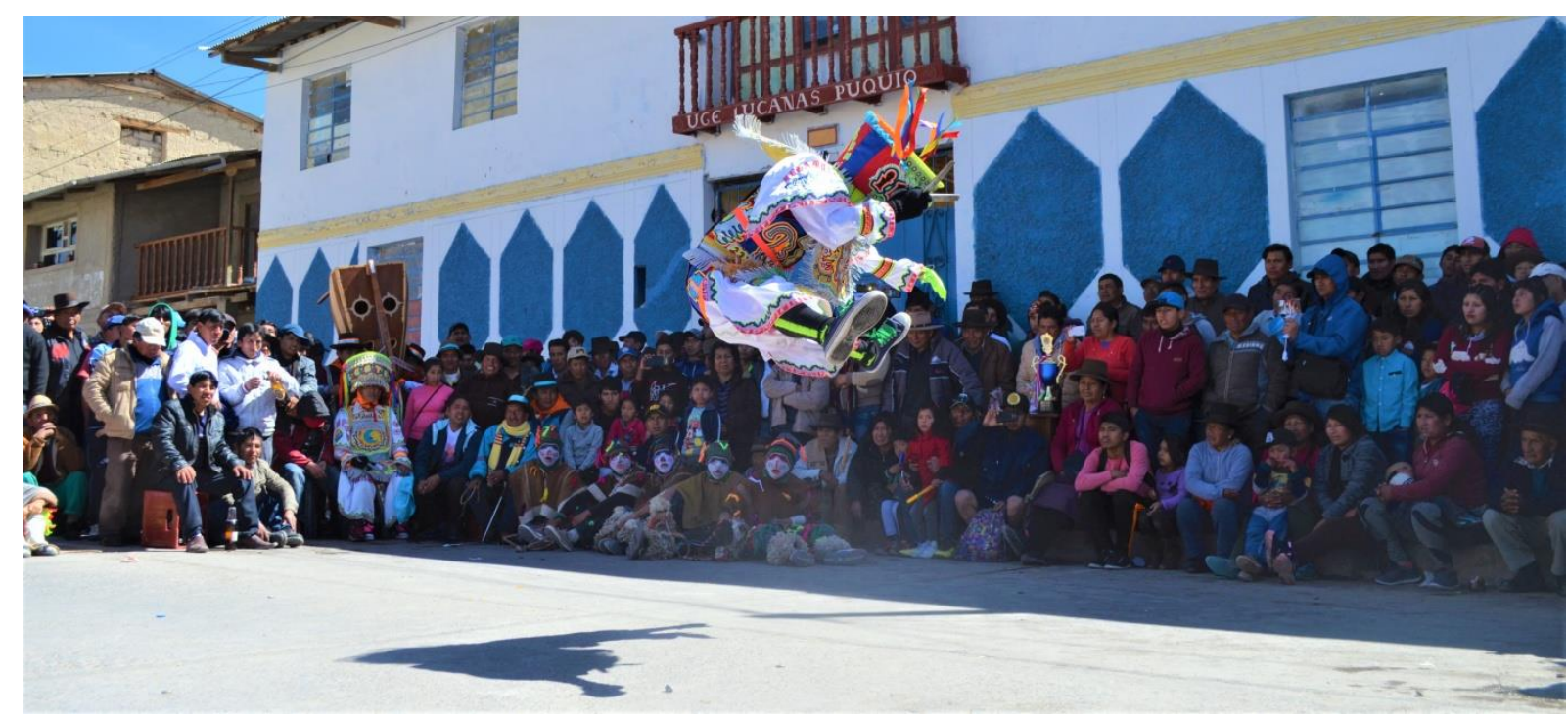

Fotografia 3 -Danzante de Tijera na Sequia Tusuy em Puquio. Fonte: Ana Carolina Abreu. Agosto de 2017.

Sobre a vivência da dança na serra e suas diferentes maneiras de (re) existir na capital, segue o relato da Danzante de Tijeras Betty Chuquimajo (Guerreira de Coracora) de 21 anos:

\begin{abstract}
Acá en Lima -a veces por la naturaleza yo digo, aquí a veces hay mucha contaminación, no hay mucho ese contacto con tus Apus...cuando bailas allá en la sierra clarito ves la luna, clarito ves las estrellas, a veces cuando tu practicas en tu patio así en la noche, tu bailas y como que tu entregas todo lo que tu sientes, lo que te da el Apu, al aire, a la naturaleza, la tierra vive, la Pachamama ¿no? Entonces haces tu pago y así de esa manera te apoya pues la tierra ¿no? Y el agua, por eso es que bailamos también en la fiesta del agua, adoramos al agua, nuestros Apus, el agua, la tierra nos bendicen a nosotros, nos dan valor, fuerza. Esa es la diferencia, en cambio acá yo he visto que solo vamos a bailar donde hay presentaciones que son de una hora que dura. No lo ve o mucho, muy llamativo, pero allá en mi pueblo sí. Lo siento más bonito (Betty Chuquimajo (Guerreira de Coracora), 21 anos, Danzante, apud DURÁN, 2017, p.38).
\end{abstract}

No próximo tópico se busca revelar sucintamente a participação dos (as) dançantes na Festa da Água, presente na citação de Betty Chuquimajo. Meu relato dará ênfase na tonada Palhaço, uma das dezenas de tonadas presentes no atipanakuy, repertório completo dos (as) Danzantes de Tijeras.

\title{
2- A participação dos/as Danzantes de Tijeras na Sequia Tusuy
}

A festa se desenvolve geralmente por oito dias, embora durante todo o mês - e em diversos momentos do ano - sejam realizadas atividades como a limpeza dos canais de água, reuniões entre as pessoas dos diversos ayllus citados (em suas respectivas associações) para a preparação da Sequia Tusuy, bem como rituais específicos liderados pelos auquis, acompanhados de seus pongos. Para Calle (2016, p. 5), nos dias da festa, as ações devem ser 
vistas como rituais, assumidas com profunda devoção por cada ayllu e especialmente por cada cargonte, homens e mulheres da comunidade, escolhidos (as) no ano anterior, responsáveis por contratar os (as) Danzantes de Tijeras para todos os dias da festa, bem como alimentá-los e abrigá-los em suas casas, eles (as) são também responsáveis pela comida e bebida da festa, dentre outras tantas atribuições.

A participação dos (as) Danzantes de Tijeras não se restringe ao terceiro dia de festa quando é realizado o chamado atipanakuy, repertório completo de sua dança. Pelo contrário, eles (as) estão presentes em todos os dias, de maneiras distintas. $\mathrm{O}$ atipanakuy merece destaque pela sua complexidade: começa por volta das três da manhã e termina ao redor de uma da tarde. A dança completa acontece ininterruptamente, durante mais ou menos dez horas, tem por volta de trinta variações - ou momentos musicais - e o mesmo número de blocos de dança. Os (as) dançantes bailam em competição no centro da praça de cada ayllu. São três dançantes competindo em cada praça e cada um (a) tem seu harpista, seu violinista e seu "capataz" (ajudante), formando, assim, uma quadrilha.

\section{3- A Danza de Tijeras e a tonada Palhaço}

A Danza de Tijeras possui sua "origem" no que foi a região Chanka, atuais regiões de Huancavelica, Ayacucho, Apurímac e a parte norte de Arequipa. Trata-se de uma dança que conserva características da cosmovisão andina pré-hispânica, somadas a elementos de influência espanhola. Para Montoya (2010, p. 211), não se sabe quando a flauta e o tambor foram trocados pela harpa e pelo violino, o que interessa é que, sem pedir permissão, os músicos andinos, encantados pela maravilha musical destes instrumentos, com o passar dos tempos, os inseriram e os tornaram seus. As roupas dos (as) dançantes e os detalhes de sua vestimenta variam de acordo com a sua região, assim como diferem seus passos de dança. Ressalto, portanto, que aqui me refiro especificamente aos (às) Danzantes de Tijeras da região de Ayacucho.

Em seu livro intitulado Los Danzaq, Lucy Núñez (1990) afirma que a fonte principal de informação sobre o significado e a história da Danza de Tijeras é a tradição oral, que se transmite de geração para geração a partir das relações fundamentais da dança, como a de mestre-discípulo ou vive-versa e dançante-divindades (NÚÑEZ, 1990, p.33). Os padres da igreja católica inventaram a história, segundo Montoya (2010, p. 209) de um pacto secreto destes (as) dançantes com o diabo, mas não disseram que estes diabos não são diabos e sim os apus, deuses das montanhas ou huacas dos velhos tempos pré-inca e inca. Cada dançante tem seu ари protetor e um lugar sagrado (uma catarata, uma lagoa, uma nascente), onde ele (a), 
seu harpista e seu violinista recebem a energia, o ânimo, o encanto e a melodia para bailar e fazer música.

A "tesoura" que todos (as) os (as) Danzantes de Tijeras carregam em uma de suas mãos, é um instrumento que produz a música de fundo, que segue fielmente a harpa, o violino, seus pés (em particular) e a todo o seu corpo. As "tesouras" são lâminas metálicas, pesam em torno de meio quilo, possuem em torno de vinte e cinco centímetros, independentes uma da outra, são fêmea e macho e se diferenciam por seu som, grave e agudo.

A vestimenta impressiona por suas cores, bordados e ornamentos, o chapéu pode pesar entre cinco e seis quilos, leva bordado o nome do (a) artista que lhe é dado por seu mestre ou mestra. No total, a vestimenta pode chegar a pesar quinze quilos. Para exemplificar, segue alguns nomes de alguns (algumas) dançantes: Eugenio Páucar (Quri Chaki- Pés de Ouro); Rómulo Huamaní Janampa (Qori Sisicha- Formiguinha de Ouro); Fidencio Huamaní Inca (Qechele- Mau Gênio); Mario Huamaní Inca (Qoronta- Sabugo do Milho), Isabel Rivera Cuba (La Vengadorita- A Vingadorinha); Betty Chuquimajo (Guerrera de CoracoraGuerreira de Coracora) e Elizabeth López Ysase (Palomita de San Antonio de PuquioPombinha de Santo Antônio de Puquio).

Cada tonada tem seu som e sua dança. Para o senhor Danzante de Tijeras Juan Quispe Rojas, que eu pude entrevistar em 2017 na Sequia Tusuy, o mais difícil é manusear a "tesoura" de acordo com a música, ou seja, bailar o ritmo de acordo com cada tonada. No livro Taki Onqóy: Danzantes de Tijeras o dançante Fortunato Anchita Aldoradin (2005, p.36 37) compartilha o nome das tonadas em sequência, presentes no atipanakuy, também conhecido como Danza Mayor que segundo ele é distinto da Alba (Danza Menor). Trata-se do Pasacalle, Plaza Yaycuy, Tonada, Juego, Siu Sal, Alto Ensayo, Pampa Ensayo, Zapateo, Negrito, Wallpa Waq'ay $\left(1^{\circ}\right.$ e $\left.2^{\circ}\right)$, Tipac Tipac (1 e $\left.2^{\circ}\right)$, Inkaiko, Wamanguina, Payaso, Cascabelina, Patara, Prueba, Pasta, Torre Bajay ou Q'erro Q'espey, Agonia, Mala Vida e Raqui Raqui ou Despacho.

Todas as tonadas me chamaram a atenção, as vi em Lima, fragmentadas, como espetáculo e posteriormente sua sequência completa (atipanakuy), nas festas andinas. Ressalto que, nestas últimas, a competição fica acirrada, uma vez que o público se expressa, critica, elogia, estimula e decide quem foi o (a) melhor danzaq. Público este acostumado com o universo que ali se apresenta e que conhece muito bem cada uma das tonadas. Inclusive, a destreza, força e beleza dos passos, bem como o manuseio da "tesoura" para a produção do som, não são suficientes neste contexto. Em suma, não basta bailar bem, importa também mostrar a energia secreta na tonada Prueba, onde cada dançante realiza em torno de três 
provas, dentre elas: comer uma rã, um sapo ou uma cobra vivos, introduzir pela boca até o estômago uma ou mais espadas, suportar o peso duas ou três vezes superior ao seu próprio peso, colocando-se sobre espinhos ou vidros quebrados e etc.

Diante de toda essa "seriedade", concentração, competição, meio a todo esse contexto espiritual desafiador e coreográfico, aparece a tonada Palhaço. Trata-se de uma parte cômica e que envolve diretamente o público. Encantou-me ver que, além de dançarinos (as), acrobatas, dotados (as) do poder dos wamanis, estes (as) artistas rituais também são cômicos (as). Em 2016, eu não podia acreditar no que estava vendo e retornei em 2017 para acompanhar todo o atipanakuy e registrar do início ao fim a tonada Palhaço. Cada um dos três dançantes que bailaram na praça de Qayau em 2017 -são eles: Hatun Mayu (Grande Rio), Supay Amaru (Serpente Demônio) e Relâmpago de Poma - realizou duas "palhaçadas", um após o outro, completando, assim, seis "palhaçadas”.

\section{1- Tonada Palhaço- primeira versão}

Já era por volta das dez da manhã e os dançantes bailavam desde a gélida madrugada. Parecia-me impossível a força física e espiritual desses corpos em suportar essa jornada ritual. Num repente, a tonada se modificou, estava mais tranquila, mais alegre, se iniciava naquele momento a tonada Palhaço. Ressalto que o grande público ao redor dos dançantes já havia tomado muita bebida alcoólica. O sol estava forte e a praça estava lotada de mulheres, homens, crianças, idosas (os) e barraquinhas de comida e bebida. Tinham pessoas até em cima das torres da igreja, próximas aos sinos.

Na primeira tonada Palhaço o primeiro dançante convidou dois homens do público para participar. A disposição e a vontade dos presentes em fazer parte deste momento eram enormes. O danzaq colocou o primeiro convidado com as mãos no chão, cabeça para baixo e pernas esticadas com as nádegas para cima. Pegou um balão cheio de ar e foi dançando lentamente, tocando sua tesoura ao som da harpa e do violino na direção do participante, fez uma pausa e num repente estourou o balão no corpo do mesmo (ver fotografia 4). Todos riram bastante. 


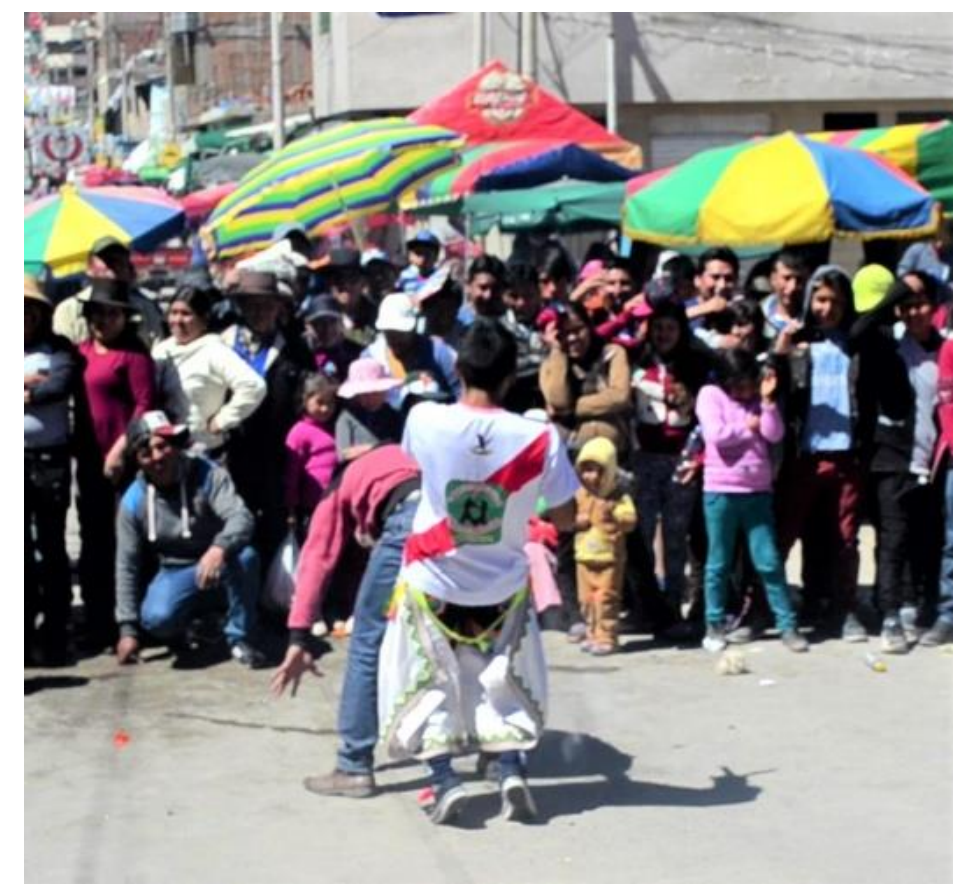

Fotografia 4 -Danzante de Tijera na tonada Palhaço. Fonte: Ana Carolina Abreu. Agosto de 2017.

Na sequência o "capataz" trouxe mais um balão, o dançante o segurou na altura das nádegas do mesmo homem. O segundo participante fez como o dançante, mas dessa vez tomando distância, correndo e acertando o "alvo" com veemência. O balão foi estourado e todos riram muito. Vale ressaltar que desta vez tinha farinha dentro do balão, deixando a calça do participante toda suja. Outro balão surgiu e a ação se repetiu. Na sequência, o dançante indicou que os papeis seriam trocados. Aquele que teve os balões estourados, estouraria os balões no outro participante. O participante que agora iria estourar o balão imitou um toro, arrastou os pés no chão, bateu no peito, correu e partiu para cima do outro participante. Pelo forte impulso ambos os participantes caíram no chão e todos riram muito. Outro balão surgiu e a ação se repetiu, mas dessa vez no momento do estouro o dançante fez uma "pegadinha" e retirou o balão, entretanto, deu tempo do participante reagir, ele parou antes de chocar seu corpo com o do outro homem. Outro balão e o dançante conseguiu tirar o balão a tempo e o participante caiu na "pegadinha", colando seu corpo no do participante. Novamente, pela força do impulso, um caiu em cima do outro, levando o público às gargalhadas (ver fotografia 5). Última vez e o balão foi novamente estourado. O dançante finalizou essa tonada Palhaço cumprimentando, agradecendo os participantes e saudando o público. 


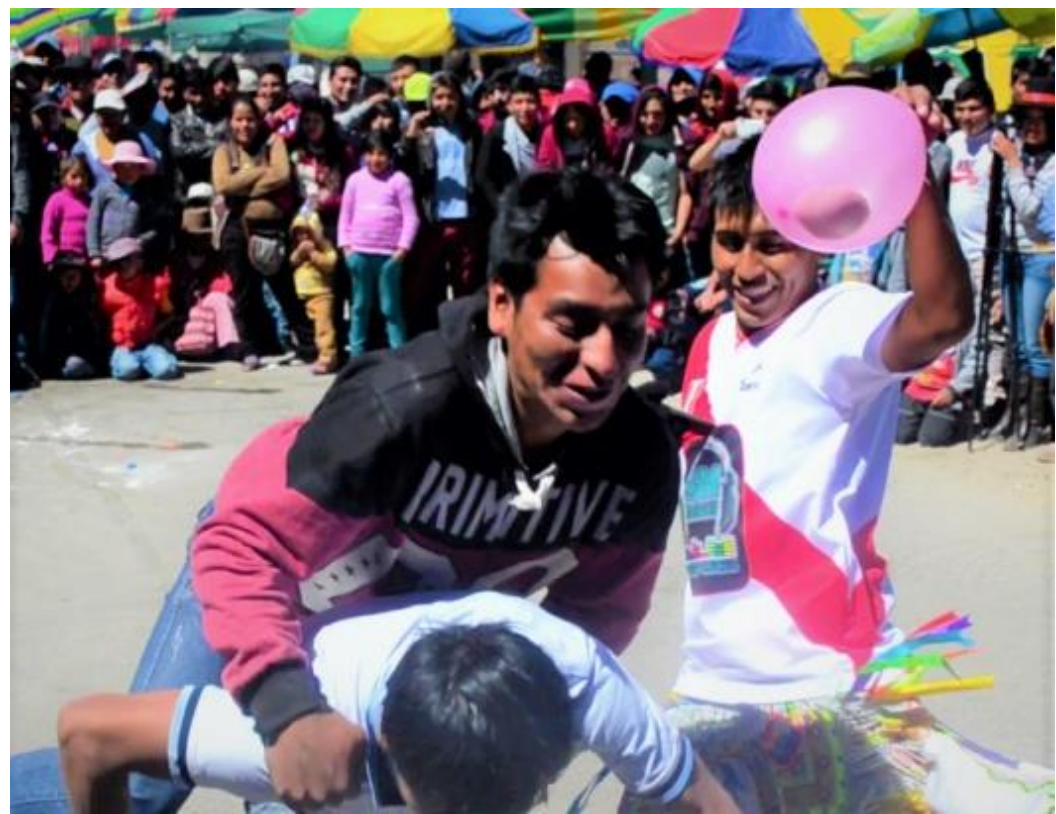

Fotografia 5 -Danzante de Tijera e participantes na tonada Palhaço. Fonte: Ana Carolina Abreu. Agosto de 2017.

\section{2- Tonada Palhaço- segunda versão}

O segundo dançante convidou dois participantes que tiveram seus braços amarrados para trás com fitas isolantes. Nesta posição eles foram colocados deitados no chão e de barriga para baixo. Ao lado oposto de cada homem foi colocado uma garrafa aberta de cerveja (ver fotografia 6). Cada homem deveria alcançar sua cerveja. Desta forma, estimulados pela música e pelo público, eles remexiam seus corpos e tentavam a todo custo se movimentar. Quando um dos participantes se aproximou da garrafa, foi puxado de volta, arrastado no chão pelas pernas, e assim sucessivamente, até que mais uma vez ambos chegaram próximos da cerveja. $\mathrm{O}$ homem que chegou primeiro permaneceu deitado, abriu sua boca e teve nela e no seu corpo toda a cerveja derramada, esse foi seu prêmio. O público foi ao delírio! O homem que ficou em segundo lugar foi desamarrado e para a sua alegria levou a cerveja para si. 


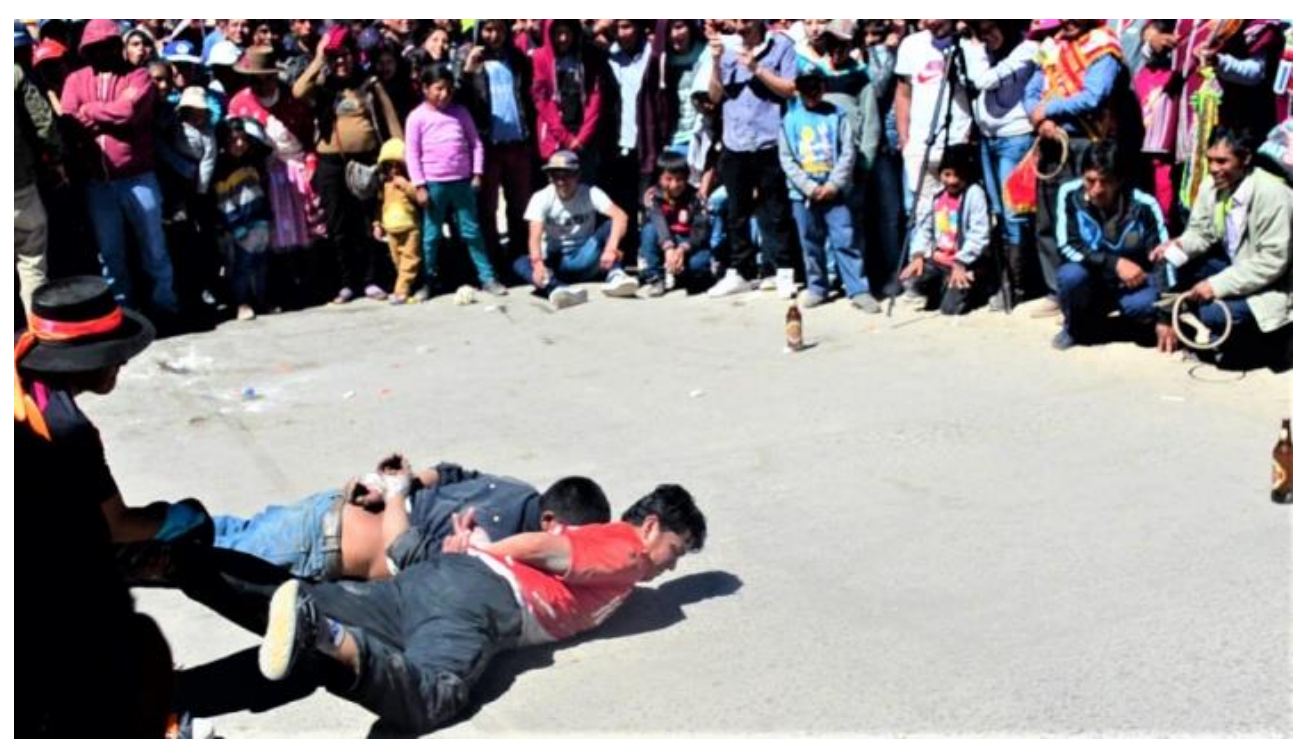

Fotografia 6-Danzante de Tijera e participantes na tonada Palhaço. Fonte: Ana Carolina Abreu. Agosto de 2017.

\section{3- Tonada Palhaço- terceira versão}

Na sequência, o terceiro dançante convidou dois homens para a sua "palhaçada" e pediu para que ambos tirassem suas camisas. O público se deliciava e ria de ambos os corpos que iam sendo revelados. O dançante os colocou sentados no chão e com um super bonder, colou dois ovos crus nos seus mamilos. No ano anterior, outro dançante havia feito essa mesma "palhaçada", mas de maneira distinta: o ovo foi colado na testa dos participantes. Todos se levantaram e a "brincadeira" se iniciou. Primeiro o dançante fez um "aquecimento" e pediu para que os participantes o imitassem. Ele tocou sua "tesoura" e fez caminhando um movimento com a cintura. Os participantes, um de cada vez, imitaram o danzaq, o público caiu na gargalhada (ver fotografia 7). Na sequência o dançante lançou um ovo (cru) no ar por vez para cada participante, o que conseguisse estourar mais ovos com a boca ganharia a competição (ver fotografia 8). Assim foram uma média de doze ovos, seis para cada um. Os ovos foram estourados pelas bocas dos participantes que escorriam pelos seus rostos, corpos e pelo público ao redor. 

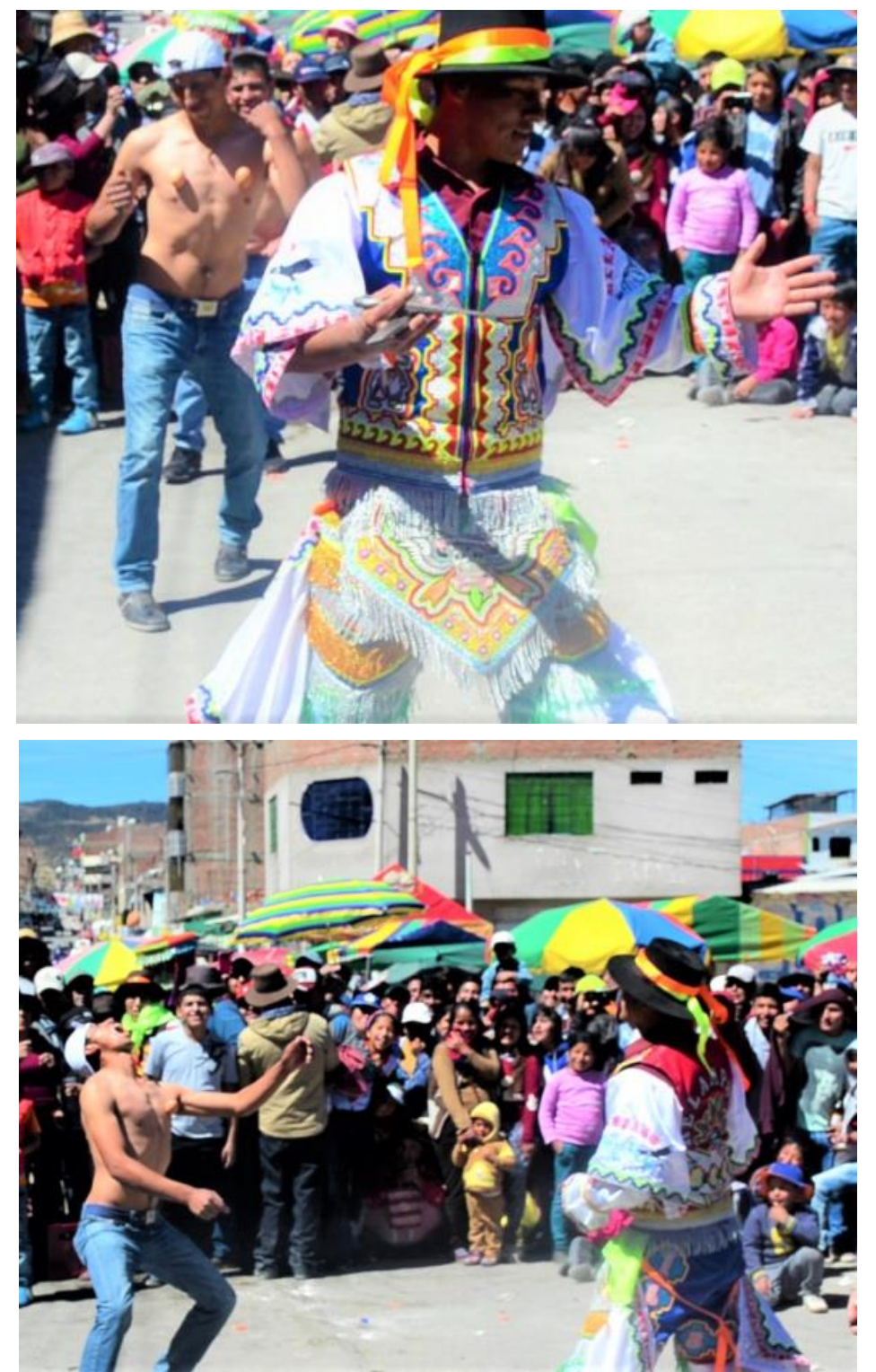

Fotografia 7 e 8 -Danzante de Tijera e participantes na tonada Palhaço. Fonte: Ana Carolina Abreu. Agosto de 2017.

\section{4- Tonada Palhaço- quarta versão}

$\mathrm{Na}$ sequência, o primeiro dançante realizou a sua segunda tonada Palhaço. Ele apareceu com uma máscara de monstro, uma sombrinha aberta, dançando no ritmo da tonada e tocando a sua "tesoura". Convidou uma moça jovem da plateia para entrar debaixo de sua sombrinha, ambos caminharam dançando a tonada juntinhos. O dançante tirou a máscara e revelou seu belo rosto (ver fotografias 9 e 10). Lembrando que, neste momento, ele não está com o chapéu típico que os danzaq utilizam em outras tonadas e que cobre boa parte de seu rosto. Assim, na tonada Palhaço, podíamos ver e reconhecer esses dançarinos. O danzaq pegou um pedaço de papel que parecia uma carta de baralho e colocou primeiramente na sua bochecha, chegou próximo da moça e sugeriu que a mesma desse um beijo naquele local, por 
cima da carta. Na sequência, o beijo foi dado na testa, na orelha, no nariz e na boca do dançante. Na boca, foram três vezes. Entretanto, na terceira vez, o dançante tirou o papel e o beijo foi, de fato, na boca. Todos riram e comemoraram o beijo! Nas outras vezes, mesmo com o papel, o beijo era comemorado pelo público com a mesma veemência que se comemora um gol, imaginem o beijo na boca! O público foi à loucura!

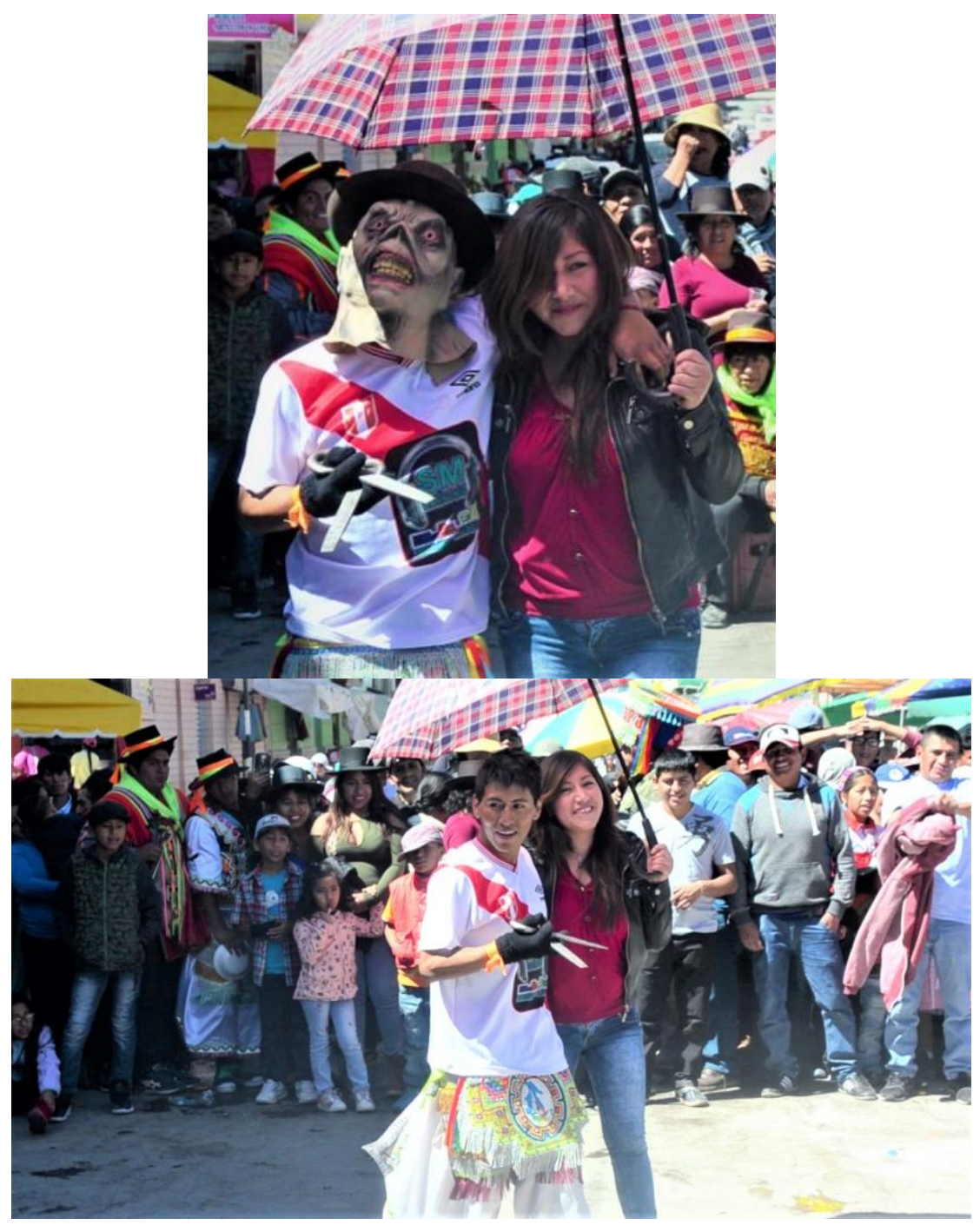

Fotografia 9 e 10 -Danzante de Tijera e participante na tonada Palhaço. Fonte: Ana Carolina Abreu. Agosto de 2017.

\section{5- Tonada Palhaço- quinta versão}

O segundo danzaq começou sua segunda tonada Palhaço, dois participantes foram convidados, ambos apareceram num repente fantasiados de mulher. Tocando sua "tesoura", acompanhado por seu harpista e violinista o danzaq propôs um "jogo": o que ele fizesse deveria ser imitado pelos participantes, um de cada vez (ver fotografia 11). Tratou-se de caminhadas, como um desfile, mas com diversos movimentos, rebolados com a cintura, beijos 
para a plateia e etc. A esta altura do atipanakuy, os llamichu começaram a chegar à praça, eles potencializaram a "brincadeira". Agora o público se divertia com a imitação dos participantes que exageravam os passos do danzaq e mais ainda, riam das paródias que os llamichu começaram a fazer deste "desfile". Para a surpresa dos participantes o danzaq os arrancou as perucas, revelando novamente os homens que estavam participando da brincadeira. Os participantes ficaram surpresos e se esconderam meio ao público, rindo muito.

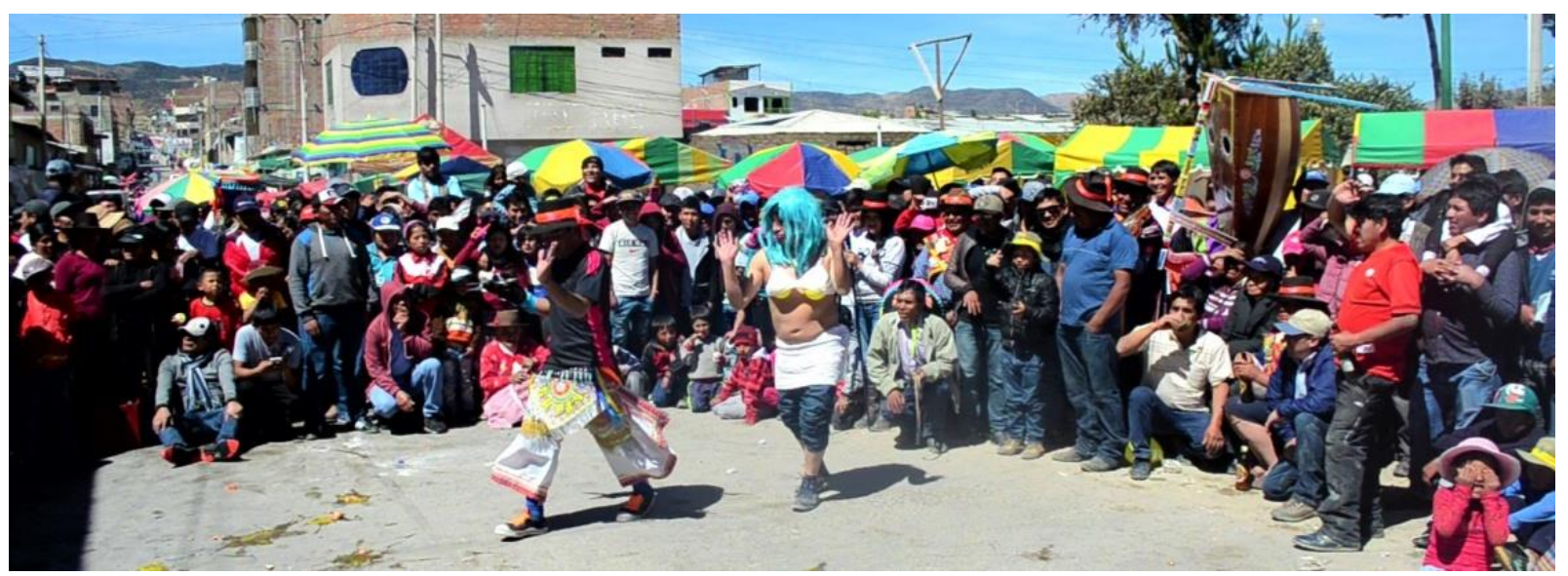

Fotografia 11 - Danzante de Tijera e participante na tonada Palhaço. Fonte: Ana Carolina Abreu. Agosto de 2017.

\section{5- Tonada Palhaço- sexta versão}

O terceiro danzaq deu início a sua segunda tonada Palhaço, dezenas de llamichu participaram improvisando com o público e ativamente na "brincadeira", dando um show à parte. Se algum llamichu extrapolava e atrapalhava o danzaq, este era retirado ou pelo "capataz" ou por alguém do público. O danzaq convidou quatro llamichu e um homem para esta "palhaçada", que ficaram dispostos em fila, um atrás do outro, ajoelhados. Ambos com um prato de plástico fundo sendo segurado pelas suas mãos, na altura da cabeça. $\mathrm{O}$ danzaq encheu de cerveja cada um dos pratos (ver fotografia 12). O "jogo" parecia consistir em derramar a cerveja de um prato ao outro até chegar à boca do primeiro llamichu que se encontrava de frente para a fila. Entretanto, de surpresa, no decorrer da "brincadeira" o danzaq se colocou atrás do homem que era o último da fila, tomou distância e o empurrou com muita força. O homem derrubou o llamichu que estava à sua frente, que por sua vez derrubou o outro llamichu, sucessivamente, como um dominó. A cerveja se espalhou para todos os lados (ver fotografia 13). O homem foi arremessado tão longe que caiu com a cabeça ao chão e ali ficou por um tempo, desacordado. Sua esposa apareceu para ajudar, o homem se levantou, colocou seu boné, limpou o rosto e riu para o público e com o público. 


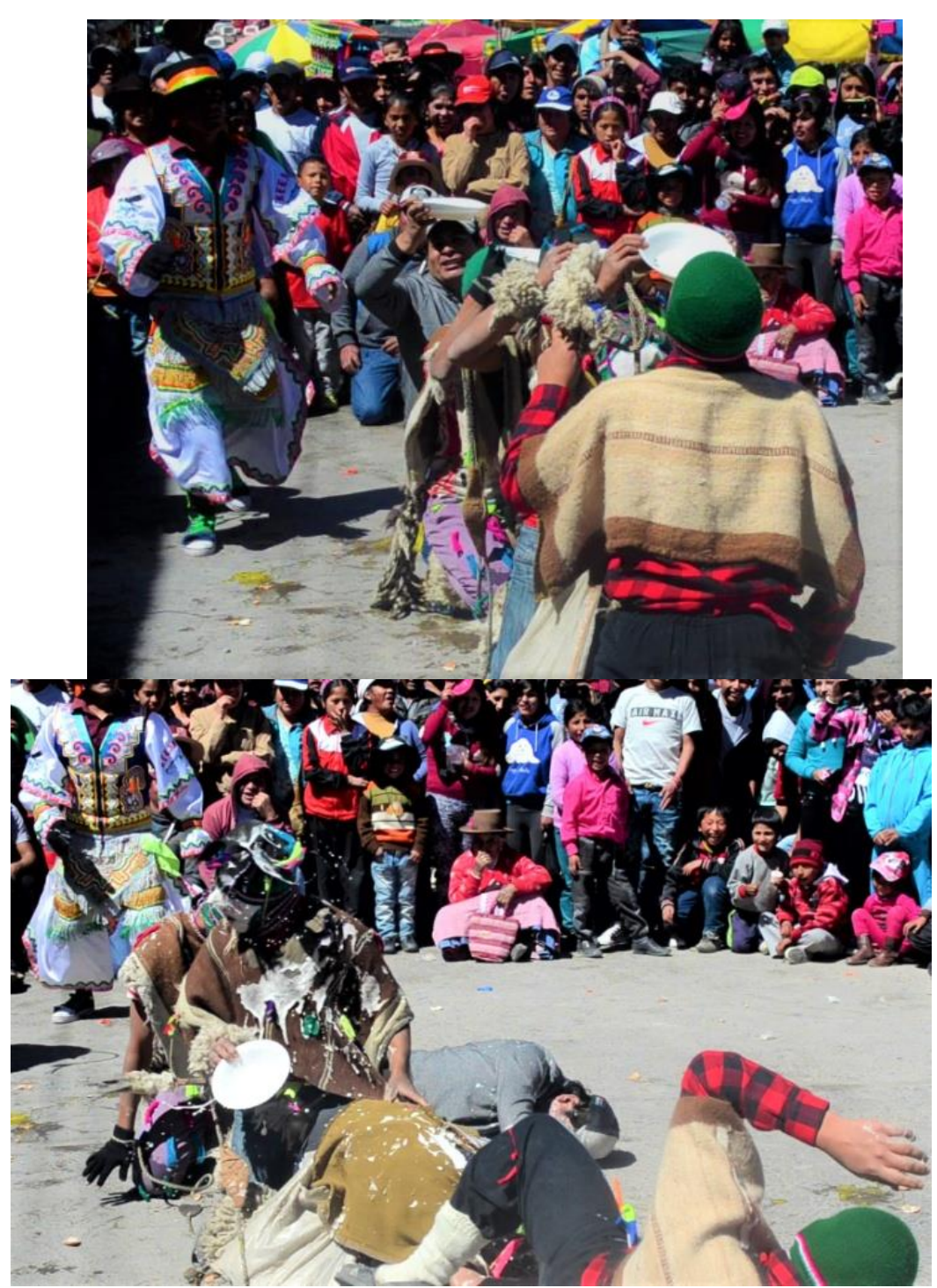

Fotografia 12 e 13 -Danzante de Tijera, participante e llamichu na tonada Palhaço. Fonte: Ana Carolina Abreu.

Agosto de 2017.

\section{4- Ao final: dançar segue sendo resistir}

Por fim, este foi um grão de areia frente ao mar aberto e complexo do universo que envolve os músicos e os (as) Danzantes de Tijeras da região de Ayacucho, Peru. É importante dizer que, mesmo sendo considerada em 2010 pela UNESCO como Patrimônio Cultural Imaterial da Humanidade, seus músicos e seus (suas) dançantes, em sua grande maioria vivem em duras condições na capital e em outras cidades do Peru. Eles (as) não possuem assistência médica e não existem políticas públicas, nem apoio e ações do Governo para estes (as) artistas. A ideia de que o reconhecimento da Danza de Tijeras como patrimônio ter representado meramente um apoio nominal que não beneficia de modo concreto os (as) dançantes e músicos, está presente no imaginário da comunidade relacionada à Danza de 
Tijeras. Por outro lado, como afirma a pesquisadora Cinthia Durán (2017), “(...) la idea de que este reconocimiento les ha abierto puertas de espacios culturales en la capital y de diversos espacios escénicos en el exterior también es recurrente entre danzantes, lo cual los llena de mucho orgullo" (DURÁN, 2017, p.33). Para o músico violinista Andrés Chimango Lares, um dos principais gestores do reconhecimento da Danza de Tijeras como patrimônio a nível nacional e internacional:

Desde la nominación hasta ahora no hay nada, en el caso mío perdón, pero yo que paro viajando todos los años a diferentes continentes, no hay un apoyo de vida. Yo he tocado las puertas del ministerio de cultura, he ido a properu, inclusive la misma UNESCO. No hay fondos. Siempre toda la vida que no hay no hay. Pero cuando tu eres una persona que tienes amigos que influyan, ahí si no? te dan, o si tienes un apellido extranjero, un apellido que suene, lo clásico no?, una persona blanca, de buena presencia, pero al hombre trigueño, al hombre que es de los andes, "disculpe no" o bien te mandan un carta por internet, o te mandan a tu casa y nada más. Entonces toca buscar el apoyo de las amistades, de amigos e empresarios o hacer eventos de un mismo para poder acatar fondos (Andrés Chimango Lares, Violinista, apud DURÁN, 2017, p.33).

Para o jovem danzaq Alberth Muños (Ação de Coracora):

(...) eso- el reconocimiento como patrimonio-lo están aprovechando los danzantes mayores que están metidos en eso. Ellos lo están aprovechando al máximo, pero nosotros no...tu eres reconocido, pero ¿que nos da a nosotros? ¿en que nos sirve? Si a nosotros no nos dan nada (Alberth Muños (Ação de Coracora), Danzante, apud DURÁN, 2017, p.33).

Segundo Andrés Chimango Lares a partir da entrevista concedida a Durán (2017), os objetivos principais que motivaram os (as) danzaq e músicos a fazerem a petição de reconhecimento da Danza de Tijeras como patrimônio são: conseguir fundos para dignificar a vida dos velhos (as) maestros e fornecer a eles (as) acesso a saúde e conseguir financiamento para abrir espaços de transmissão de conhecimentos ancestrais à geração de jovens herdeiros desta dança.

Nos congressos destes (as) artistas que participei seja em Ayacucho, Lima ou Huancavelica, as urgências são as mesmas, todos repetem o fato de que não há apoio econômico para desenvolver e implementar os projetos de salvaguarda da dança, nem para cobrir as necessidades essenciais da comunidade de mestres (as). Além disso, eles (as) revelam em suas declarações a discriminação que sofrem a nível institucional e social apesar de serem reconhecidos oficialmente como patrimônio.

Ao final, o que se pode observar é que a "legitimação" da dança se converteu em uma ferramenta de revindicação, visibilidade, empoderamento e inclusive de mobilidade econômica, ou seja, representou um grande passo para a comunidade de dançantes. Desta 
maneira a Danza de Tijeras seque sendo uma forma de resistir, de dar continuidade a uma identidade cultural.

\section{Referências Bibliográficas}

ALDORADIN, Fortunato Anchita. Taki Onq'oy: Danzantes de Tijeras. Fondo Editorial del Ministerio de Educación em Lima, 2005. (Obra Completa)

ARGUEDAS, José María. Yawar Fiesta. Lima: Editorial Horizonte, 1983. (Obra completa)

CALLE, Juan Francisco Tincopa. Sekia: Yaku Raymi, la fiesta del Agua. Revista Mirador Chanka, n 11, 2016. (Artigo em Periódico Físico)

DURÁN, Cinthia. La Danza de las Tijeras: continuidad dinámica y reinvidicación de la identidad indígena andina. 2017. 52 f. Monografia (Skidmore College- Relaciones Internacionales con enfoque regional en América Latina; y Estudios de Investigación en Danza)- Programa Perú: Pueblos indígenas y Globalización, SIT Study Abroad, Lima, 2017. (Dissertação ou Tese)

MONTOYA, Rodrigo Rojas. En defensa del nevado Qarwarasu, su agua-vida-fiesta, y sus danzantes de tijeras. Julho de 2015. Disponível em: https://redaccion.lamula.pe/2015/08/10/en-defensa-del-nevado-qarwarasu/albertoniquen/.

Acesso em: 3 de julho de 2018. (Artigo em Periódico Digital)

Porvenir de la cultura quechua en Perú. Lima: Fondo Editorial de la Universidad Nacional Mayor de San Marcos, 2010. (Obra Completa)

NÚÑEZ, Lucy Rebaza. Los Danzaq. Lima: Museo Nacional de la Cultura Peruana, 1990. (Obra completa) 